\title{
Considerações sobre o Mercosul
}

\section{RICARDO SEITENFUS}

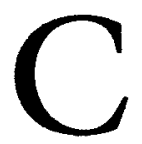

aracterizado ao longo da história por frio desconhecimento ou por oposiçōes veladas, as relações argentino-brasileiras sofrem um processo de profunda transformação nesta última década. Ultrapassado o litígio em torno dos recursos hidrográficos compartilhados, pressionados internamente pela construçáo da democracia e externamente por uma crise que reduz seu espaço no sistema internacional, as vozes que advogam um relacionamento construtivo na Bacia do Prata se vêem reforçadas. É neste cenário que são firmados, em julho de 1986, os primeiros Protocolos de Cooperação, abrangentes e profundos, que estão na raiz do Tratado de Assunção, firmado em março de 1991, incorporando quatro dos cinco países da Bacia.

A operacionalização das decisóes de Assunçăo, através da adoção de ousado cronograma em Las Leñas, em junho de 92, significa reversão tăo significativa quanto inesperada das relaçōes entre Brasília e Buenos Aires, que se torna difícil para os analistas identificarem todos os contornos do processo de cooperação. O que se nota então é uma avalanche de estudos abrangentes ou setoriais, oriundos sobretudo de consultorias independentes ou do meio acadêmico. As páginas a seguir têm a única pretensão de contribuir para o debate, oferecendo de forma sucinta algumas reflexōes sobre questóes que nos parecem pertinentes.

Iniciaremos apresentando o atual cenário econômico internacional com suas principais características e inserindo neste o processo de integraçăo do Mercosul, buscando as motivaçóes tanto internas quanto externas à realização desse entendimento. Em seguida analisaremos através de um organograma o Tratado de Assunçāo, suas características e prazos de implementaçáo. Finalmente, colocaremos algumas questóes que para nós permanecem sem resposta no processo de transição que atualmente vivenciamos, especialmente as questóes envolvendo a institucionalização, as relaçōes entre o Mercosul e NAFTA e alguns setores sensíveis. 


\section{O cenário econômico internacional}

Dois são os fenômenos que moldam as relaçóes econômicas internacionais na atualidade: a globalizaçáo e a regionalizaçāo. A primeira surge neste século, em especial após a Segunda Guerra Mundial, quando as forças isolacionistas nos EUA são suplantadas pelos internacionalistas fazendo do globalismo o catalisador das relaçóes internacionais.

Homogeneizaçáo dos métodos produtivos, dos gostos dos consumidores, fusōes e incorporações de empresas, papel progressivamente menos relevante do Estado na circulaçáo de capitais, independência das empresas em relação a mercados nacionais, comércio internacional movimentando mais de um trilhão de dólares anualmente constituindo importante mola do desenvolvimento, modernizaçáo dos meios de comunicaçáo e de transportes, desregulamentação das atividades de produção e os progressos tecnológicos são alguns elementos a fazerem com que se internacionalizem os processos econômicos.

O segundo fenômeno marcante do sistema internacional é o entendimento regional. Cimentado pela vontade comum de superar rivalidades do passado, baseado em contigüidade geográfica e pressupostos ideológicos com valores políticos e morais compartilhados, ele inicia-se por um processo de aproximação pontual, geralmente de caráter comercial. Algumas ou todas essas premissas estáo presentes nos processos de integração que se desenvolvem atualmente.

$\mathrm{Na}$ Europa o processo de integração é múltiplo: político, parlamentar, cultural, educacional, em C\&T mas, sobretudo, sem sombra de dúvida, econômico. Conduzido em seu início com exclusividade pelos Estados, nos últimos anos o setor privado tem participado nesse processo, percebendo ser tão somente através da conjugação de esforços que poderá enfrentar a concorrência em um mundo globalizado. A confirmação da importância dos países da Bacia do Pacífico com o progressivo deslocamento do centro de gravidade tecnológico e financeiro para essa regiáo, convence a Europa Ocidental que somente a união lhe permitirá ocupar lugar de destaque no sistema econômico internacional.

$\mathrm{Na}$ América do Norte, os governos do Canadá e EUA oficializam, através de um tratado comercial, uma relação econômica já privilegiada. Com efeito, a fronteira política EUA/Canadá nunca foi entrave ao intenso intercâmbio. A novidade fica por conta da participaçăo formal do México no North American Free Trade Agreement (NAFTA). A inclusão desse país no espaço econômico norte-americano atualmente já é realidade. No entanto, do ponto de vista político e cultural a transferência de uma das sociedades mais representativas da realidade latino-americana - como é o caso da sociedade mexicana - para um espaço domi- 
nado por valores anglo-saxônicos, năo deixa de provocar sentimento de perplexidade.

Na Bacia do Pacífico o processo de aproximação entre países com diferenciados níveis de desenvolvimento econômico é conduzido praticamente sem intervenção governamental. Centrado em torno do Japáo, o processo baseia-se em políticas de promoçăo das exportaçóes visando aos mercados norte-americano e europeu.

No continente africano a maioria dos países possui relaçóes privilegiadas, de caráter vertical, com França e Reino Unido. A Comunidade Econômica Européia definiu, através dos Acordos de Lomé, bases de relacionamento privilegiado com a África, mas esta não conseguiu ainda estabelecer estratégia comum de aproximaçáo econômica.

Finalmente, a Europa do Leste, em confronto com as opções de concertaçáo regional e globalismo, parece escolher uma terceira via, a da fragmentaçáo. A falta de recuo temporal talvez não permita que possamos visualizar com clareza o itinerário do ex-império soviético. Provavelmente a discórdia atual seja consequiência de décadas de submissão e passado o momento de contestação a regiáo reencontre um ponto de equilíbrio em suas relaçōes recíprocas e com o resto do mundo. No entanto, cabe salientar estar a regiáo em condiçóes bem menos favoráveis do que, por exemplo, a América Latina, para inserir-se no globalismo e serão necessárias geraçóes para criar espírito empresarial, condiçăo sine qua non da economia de mercado.

\section{Por que o Mercosul?}

Tornou-se lugar comum considerar os anos 80 como sendo a década perdida para a economia latino-americana. Esgotou-se o processo de substituição das importaçóes que esteve na raiz do desenvolvimento da economia da América Latina sem se poder vislumbrar com clareza a nova inserção internacional da região.

Indicadores sociais em acentuada queda contrastando com o contínuo crescimento demográfico, altas taxas inflacionárias, crise do Estado que se mostra incapaz de continuar a investir em programas sociais e de infra-estrutura, crescimento desmedido da dívida interna e externa tornando a América Latina exportadora de capitais, queda de $12 \%$ para $4 \%$ da participação da região no comércio internacional, são algumas das evidências da crise da economia latino-americana.

A situação é ainda mais grave na medida que sua economia tem demonstrado competência na produção dos bens que não se incluem no rol dos mais dinâmicos. Nestes últimos, produtos com elevado índice tecnológico, a região é pouco competitiva, como demonstram os mais recentes trabalhos do embaixador Rubens Ricupero. $O$ espaço ocupado 
no orçamento estatal pelos investimentos em C\&T tende a reduzir-se, o que provocará certamente o agravamento da situaçáo. Este quadro tornase ainda mais dramático quando comparado com o que ocorre no sudeste asiático.

Essas circunstâncias favorecem o resgate de idéias elaboradas pela Comissão Econômica para a América Latina e Caribe (CEPAL) das Naçóes Unidas e de seu principal inspirador, Raul Prebisch, que advogavam já na década de 50 a necessidade de aproximação entre as economias latino-americanas para buscar maior eficiência e melhor utilizaçăo de seus recursos materiais, financeiros e humanos.

Inscritos nesse contexto os governos da Argentina e do Brasil decidem, pela primeira vez em sua história, por uma aproximação múltipla que marca a evolução política e econômica no Cone Sul.

Sem desconsiderar a importância dos aspectos estratégicos e da necessidade de reunir forças para melhor se inserir no sistema econômico internacional, caracterizado pela progressiva formaçáo de blocos econômicos, o objetivo fundamental do Mercosul é a busca do crescimento econômico. Constituindo reiteração dos princípios norteadores dos protocolos argentino-brasileiros resumidos na idéia de crescer juntos, os quatro países, cientes que o Norte desenvolvido engolfado por seus problemas não oferece condiçóes de cooperação semelhantes àquelas dos anos 50 e 60, pretendem aumentar sua competitividade internacional com incremento da produtividade e investimentos tecnológicos e modernizaçáo do processo produtivo. Para tanto, é necessário diminuir a intervenção estatal através de uma política de privatização, canalizar investimentos para as áreas mais competitivas, liberalizar a economia através da diminuiçáo do controle de preços e das tarifas de proteção, colocando as economias nacionais paulatinamente em confronto na competição internacional.

Essa vontade expressa nos vários documentos firmados entre os. quatro países deveria criar, ao longo do processo de transição, uma cultura comunitária; condiçăo sine qua non para possibilitar a existência de um mínimo de disciplina comum, que seria alcançada ao longo do processo de transiçăo.

Com realidades econômicas díspares nos seus mais variados aspectos - nível de intervençáo estatal, patamar de desenvolvimento, dimensão de mercado -, mas também com notáveis desníveis de motivação em torno do processo mercosuliano, torna-se praticamente impossível fazer com que as decisóes comunitárias encontrem eco uniforme nas economias dos quatro países. O Tratado de Assunçăo reconhece, a sua maneira, essa dificuldade quando concede ao Paraguai e ao Uruguai doze meses de carência para que adotem igualmente a tarifa zero. 
Por outro lado, há percepçáo diferenciada do Mercosul entre os quatro membros, segundo o grau de abertura de suas economias para terceiros mercados. Assim ficou claro que para o Uruguai a opção mercosuliana está no âmago de todo o planejamento de desenvolvimento do país. Com grande tradição liberal, caracterizada pelo livre trânsito de bens, capital e pessoas, o Uruguai parece demonstrar ser o mais apto e talvez o mais interessado no pleno sucesso do Mercosul.

O Paraguai, por sua vez, com população predominantemente rural e com sistema comercial bastante singular, por baixíssima tarifa externa, visualiza o Mercosul com interesse e apreensão. $O$ interesse é conseqüência das relaçóes econômicas privilegiadas com os três parceiros e a apreensão nasce da insuficiente industrialização do país, bem como da interrogação quanto ao destino das zonas de exportação de produtos de terceiros países.

A posição argentina de adesão ao Mercosul é fundamentada essencialmente pela busca de maior eficiência, abertura econômica e consolidaçáo do processo democrático. Agregadas a essas consideraçóes, devemos salientar que a Argentina também é motivada pela possibilidade de conquista do enorme mercado potencial e real brasileiro. Portanto, no seu início, o Brasil é o merco, enquanto que os outros países são o sul, na bem humorada e pertinente trouvaille do embaixador Marcos Castrioto de Azambuja. Ora, o que assistimos agora é exatamente o contrário dessa situação, com o Brasil, segundo projeçóes, levantando no final de 1992 um superávit superior a um bilhão de dólares na sua balança comercial com a Argentina. Certamente essa situação está vinculada à supervalorizaçáo da moeda argentina, à recessăo persistente da economia brasileira que busca, então, compensação nas exportaçóes, a uma pequena defasagem cambial do cruzeiro e ao processo de abertura mais rápido da economia argentina.

A escassa elasticidade dos princípios e critérios de negociação previstos no Tratado de Assunção tendem a impedir adaptaçōes a fenômenos conjunturais nacionais. É necessário, no entanto, que o Mercosul espelho de um somatório de situaçóes internas - não venha a ser considerado o bode expiatório de políticas nacionais.

As razóes brasileiras são várias. Além de motivaçóes estratégicas, política externa e necessidade de construir uma agenda positiva na Bacia do Prata, devemos salientar que a persistente crise econômica dos anos 80, no Brasil, faz com que o país busque acentuar a sua presença no comércio internacional. O Mercosul se insere nessa perspectiva.

O Brasil possui perfil de comércio exterior extremamente diversificado, tanto no que diz respeito a importaçóes quanto a exportações. $O$ 
quadro a seguir demonstra que o interesse brasileiro em participar do processo de integração do Cone Sul representa uma forma complementar de inserção no sistema econômico internacional.

Distribuição geográfica por regiōes do comércio exterior brasileiro (1991)

REGIĀO

E.U.A.

Canadá

C.E.E.

Ásia

América Latina

África

Oriente Médio

Oceania

\section{EXPORTAÇÃO}

$19,8 \%$

$1,5 \%$

$30,9 \%$

$18,0 \%$

$16,3 \%$

$3,3 \%$

$3,5 \%$

$0,8 \%$
IMPORTAÇÃO

$23,3 \%$

$2,4 \%$

$22,1 \%$

$9,1 \%$

$18,2 \%$

$4,0 \%$

$12,6 \%$

$0,7 \%$

Fonte: FLORENCIO, S. A. L., O papel multilateral do comércio exterior brasileiro e a construçăo do Mercosul. Boletiom de integrafäo latino-americana n.7, out/dez 1992, p.23

Não se deve concluir que a participação brasileira no processo de integração no Cone Sul, região que representa índices marginais de nosso comércio exterior, seja opção excludente. $O$ pretendido é exatamente o contrário: fazer com que o processo do Mercosul constitua uma ponte para melhor desempenho econômico e mais adequada inserçáo na economia internacional.

\section{O Tratado de Assunção: características e prazos}

São duas as características primordiais das decisóes tomadas em março de 1991 na capital paraguaia: a universalização das decisōes, ou seja as decisóes afetariam o conjunto dos bens e produtos dos países membros no que diz respeito ao sistema de trocas e, por outro lado, a redução dos prazos para implementação da política de liberalizaçáo do comércio entre os quatro parceiros.

Relativamente ao comércio intrarregional, foi adotado o princípio da reduçáo tarifária progressiva, linear e automática, fazendo com que o conjunto dos produtos produzidos no Brasil e Argentina circule livremente entre os dois países a partir de $1^{\circ}$ de janeiro de 1995 . Uruguai e Paraguai associam-se a esse processo com calendário diferenciado no tempo, pois sua incorporaçáo efetiva com tarifa zero se dará em $1 \%$ de janeiro de 1996. Para que se tenha visualizaçáo abrangente desse instrumento, decidimos transcrevê-lo através do seguinte organograma: 


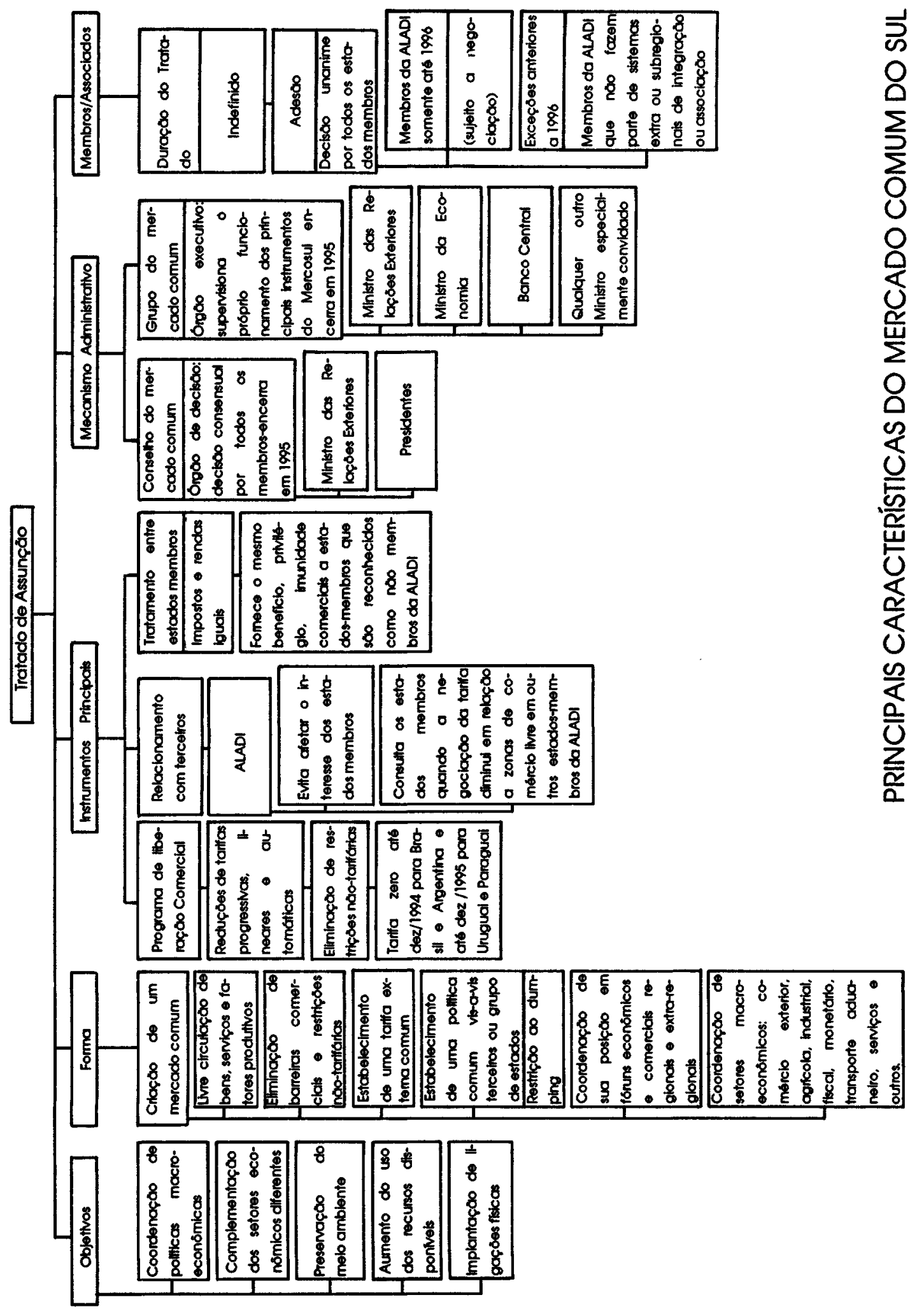




\section{Principais Características do Mercado Comum do Sul}

Os ambiciosos objetivos contidos no documento firmado em Assunção contrapóem-se ao reduzido prazo previsto para sua implementaçáo. A coordenaçáo das mais diversas formas de políticas públicas deve ser entendida como sendo " uma dessas palavras pronunciadas facilmente, mas executadas com dificuldades. Significa que cada país deve, por vezes, adotar medidas que não desejaria adotar" (Thurow, 1992). Ou seja, será necessário que cada país adote poluntariamente medidas que o aproximem dos outros três parceiros e dos objetivos comuns, mesmo que estas não correspondam fielmente às necessidades nacionais do momento. Estamos neste caso perante um dilema que somente poderá ser resolvido favoravelmente à estratégia integracionista, caso os responsáveis comportem-se como estadistas, imprimindo percepçóes de médio e longo prazos para suas ações políticas.

A adoção do cronograma de Las Leñas em junho de 1991 complementa e reforça as decisóes tomadas em Assunção. A partir desse momento os objetivos genéricos incluídos no Tratado de Assunçăo adquirem uma operacionalização visando a cumpri-los.

A conciliaçăo de interesses através de compensaçóes deve ser a base de todo o processo de negociação. Ajustes e reacomodaçóes devem sempre levar a um objetivo comum. Entretanto, quando é estabelecido um inventário das diferenças macroeconômicas entre os quatro países, devemos concordar que "o cronograma de trabalho original é espetacularmente irrealista (pois) supóe-se que em 1994 teremos regras de integração mais avançadas do que as da Comunidade Européia hoje" (Serra, 1992).

Caso o Mercosul conseguisse estabelecer zona de livre comércio nos prazos estabelecidos, seria um grande passo em direçáo ao Mercado Comum. A adoção do livre comércio para os produtos da regiáo, com a eliminação total das barreiras tarifárias e não tarifárias, a clara definição de regras de origem e $o$ estabelecimento de instrumentos independentes para a soluçăo de controvérsias seriam um patamar fundamental para a criaçáo de condiçóes para o estabelecimento posterior de uniáo aduaneira com tarifa externa comum para, finalmente, ser alcançada num terceiro momento a unificação total do mercado com a livre circulação de bens, serviços, capitais e pessoas.

O Tratado de Assunçáo e o cronograma adotado em Las Leñas reúnem num único tempo esses três diferentes momentos. Seria neces- 
sária a desvinculação dessas três etapas e a reavaliação dos prazos, porque a história da integração econômica demonstra ser a prudência boa conselheira e nada mais perigoso para o processo do que atitudes dogmáticas sobre o ritmo e a profundidade de sua implementação (Seitenfus, 1992). A possibilidade de reavaliação do cronograma foi, pela primeira vez, levada em consideração pelo Ministro da Economia da Argentina - Domingo Cavallo -, dada a continuidade das divergências macroeconômicas, sobretudo a defasagem cambial, que ponderou: "se for preciso sacrificar algo, não são as instituiçóes que queremos edificar (no Mercosul) e sim o tempo de que precisaremos para fazê-lo" (Cavallo, 1992). A possibilidade da manutenção dos prazos estabelecidos em Assunção deve ser entendida menos como resultante de profundos estudos sobre sua factibilidade e mais como expressáo da vontade da criação de um fato político. Essa estratégia, enraizada no próprio processo eminentemente político, é bastante questionável, pois certamente os atores não estatais do processo terão dificuldade em aceitar, quando da expiraçáo do prazo de transição, declaraçóes diplomáticas triunfalistas que năo correspondam à realidade, independentemente do resultado do processo de transiçăo.

\section{Algumas perguntas sem respostas}

\section{A Supranacionalidade}

As concertações regionais abrangem situações muito díspares, desde a simples concessão de preferências tarifárias até a constituiçăo de verdadeiros mercados unificados com a livre circulaçáo dos fatores de produção e da cooperação em todos os campos, inclusive os não econômicos. Portanto, não será inspirados em considerações técnicas ou economicistas que devemos concluir sobre a necessidade ou năo da institucionalização do Mercosul e da concessão de direitos supranacionais. $O$ importante é conservarmos o nível de politização que está na base do processo, para definir qual será o ordenamento institucional do Mercado Comum do Sul. No entanto, parece ser inquestionável a necessidade de construir um poder comum, depositário dos interesses dos países membros, que possa fornecer a indispensável continuidade ao processo integracionista e à legitimidade da representaçăo popular. Caso não se construa este poder comum com as duas características mencionadas, o processo estará entregue às mãos dos Estados membros e da exclusiva vontade dos governos que se sucederem, sem a devida representação da vontade popular.

As liçóes do direito internacional são insuficientes para definir este 
novo fenômeno das relaçóes internacionais - a supranacionalidade. Apesar de inúmeras versōes, podemos resumir o conteúdo da supranacionalidade pela presença dos seguintes elementos: reconhecimento pelos Estados membros de valores comuns; aplicabilidade destes através da existência de poderes efetivos; indispensável poder de autonomia.

Como corolário a esta tríplice condição, da supranacionalidade efetiva decorre a institucionalizaçáo do processo, tornando-o permanente, irreversível, com poder para dirigir-se diretamente aos cidadáos, sem passar pelo Estado e, finalmente, com a possibilidade de impor-se aos Estados relutantes.

Às dificuldades inerentes para desenhar o perfil dessa instituiçăo devemos acrescentar experiências frustrantes no passado com secretariados econômicos latino-americanos e, sobretudo, com a má interpretação do liberalismo predominante na regiáo, que considera qualquer instrumento burocrático como sendo ineficiente, oneroso, pesado e passível de corrupção.

Essa maneira não infundada de visualizar a burocracia em geral e especialmente a latino-americana, coloca uma questão fundamental no processo do Mercosul: será possível fazer a integração sem a presença de um mínimo de burocracia supranacional? Quando concluído o processo de transição e atingido um patamar aceitável de simetrias, não seria importante que se delegasse a um órgáo supranacional parte da soberania econômica de cada um de seus membros para o processo ter continuidade, sem traumas, tornando-se efetivamente irreversível?

A respostas a essas questóes estáo intimamente vinculadas ao tipo de integração almejada. Caso nos contentemos em estabelecer unicamente uma zona de livre comércio, como no caso do North American Free Trade Agreement (NAFTA), a questão institucional é relativamente secundária, pois bastaria o estabelecimento de instrumentos de controle de aplicação das decisões comunitárias. Ao contrário, caso sigamos os passos da constituiçăo de um verdadeiro mercado comum, como parece indicar o Tratado de Assunção, a institucionalizaçáo requer perfil abrangente e permanente, com delegação expressa de poderes nacionais, tal como ocorre com a Comunidade Econômica Européia (CEE). Inclusive, o cronograma adotado em Las Leñas prevê para maio de 1994 decisão com relação ao perfil e atribuições específicas dos órgãos do Mercosul. Nesse sentido, o governo brasileiro solicitou ao Instituto Latino Americano (ILAM) a coordenação de um trabalho sobre as instituiçóes do Mercosul.

Como desenho institucional o Mercosul poderia inspirar-se em 
algumas experiências que ocorrem tanto na Comunidade Econômica Européia quanto na Organização Internacional do Trabalho.

Deveríamos possuir para o Mercosul três órgãos de representação que pudessem garantir processo decisional democrático, participativo e consolidado. Poderíamos imaginar, em primeiro lugar, a criação de um grupo permanente supranacional com base física estabelecida e que fosse, de certa forma, guardiáo dos interesses comuns. Em segundo lugar, trabalhar para a criação do Parlamento do Mercosul, para que este possa expressar reivindicaçōes e aspiraçōes populares, dando legitimidade direta ao processo. Finalmente, o terceiro nível institucional seria a criação de uma Corte de Justiça, como garantia do respeito aos valores jurídicos.

Esta forma de proceder assimila à institucionalização do processo do Mercosul a experiência da OIT que, como se sabe, tem uma representação tripartite, ou seja do Estado, dos delegados representantes dos empregadores e dos representantes dos trabalhadores. Assim procedendo eliminaríamos a maior distorçáo das organizaçóes internacionais, qual seja, a exclusiva e excludente representaçăo estatal (1).

\section{O Mercosul e o NAFTA}

Poderíamos imaginar que sob o guarda-chuva da Iniciativa para as Américas, apresentada pelo presidente George Bush em junho de 1990, um novo relacionamento econômico se estabeleceria nas Américas, com a criação de uma zona de livre comércio do Alasca à Patagônia. Para tanto é necessário que a Iniciativa não seja para, mas das Américas. É nesse sentido que foi firmado, em junho de 1991, o acordo conhecido como Jardim das Rosas, entre os Estados Unidos e os países integrantes do Mercosul. Pela primeira vez na história das relações comerciais interamericanas, os Estados Unidos se dispuseram a firmar acordo com um órgão multilateral latino-americano. Foi criado nessa oportunidade um Conselho Consultivo sobre Comércio e Investimentos, objetivando aumentar o grau de abertura dos mercados entre os signatários e incrementar os fluxos de comércio e investimentos (Amorim \& Pimentel, 1992).

No entanto, a grande mudança da política comercial dos Estados Unidos na região é a assinatura, em 12 de agosto de 1992, do NAFTA - North American Free Trade Agreement, Acordo envolvendo Estados Unidos, Canadá e México.

A objetividade dos propósitos contidos no NAFTA fazem com 
que o acordo do Jardim das Rosas torne-se simplesmente de intençóes diplomáticas. Os dois elementos catalisadores do comércio na regiáo estáo intimamente vinculados ao desempenho do Mercosul e do NAFTA. Eles possuem raízes, itinerário, formataçăo e expectativas completamente díspares.

O Mercosul fundamenta-se em desencontros políticos do passado, na escassa complementaridade econômica do presente, que se contrapóem à ambiciosa forma de cooperação - a construção de um mercado comum -, buscando a criação de comércio regional.

O NAFTA, por sua vez, coroa com formalidade um comércio regional intenso - cerca de $\mathbf{7 0 \%}$ do comércio exterior do México e do Canadá são feitos com os Estados Unidos. Năo pretende estabelecer formas aprimoradas de instituiçốes comunitárias, mas ser, simplesmente, zona de livre comércio.

Mesmo impossibilitados de avaliar com precisão o destino do NAFTA perante a nova administração democrata em Washington, é plausível que após algumas reacomodaçōes o acordo entre em vigor. Certamente dinamizará as economias dos três países, mas năo está excluído que ele possa, além da criaçáo de comércio, desviar fluxos comerciais tradicionais. Essas modificaçóes tenderăo a beneficiar setores exportadores mexicanos, em detrimento dos tradicionais exportadores sul-americanos para o mercado dos Estados Unidos e Canadá, como é o caso do Brasil.

É aconselhável que o Mercosul aprofunde as decisóes tomadas quando da assinatura do acordo do Jardim das Rosas, ampliando suas consequiências para os dois parceiros do NAFTA. Seria inclusive importante que o Brasil encorajasse a conclusão de um acordo MercosulNAFTA, resguardando-se assim da eventualidade de desvio de comércio e eliminando a ameaça de ver algum membro do Mercosul ser tentado a negociar, unilateralmente, acordos que violem as resoluçóes de Assunçăo.

\section{Setores Sensipeis}

Com o perfil econômico profundamente diferenciado, a sensibilidade setorial manifesta-se de forma distinta entre os quatro parceiros do Mercosul. Simplificando, poderíamos dizer que o pouco desenvolvimento industrial do Paraguai e do Uruguai, bem como a crise recessiva profunda da indústria argentina, fazem com que alguns segmentos do setor secundário desses países encontrem-se em posição delicada. $O$ Bra- 
sil, por sua vez, com um parque industrial e de serviços sofisticado e desenvolvido, deverá dar atenção especial aos produtos primários e aos setores da agroindústria que poderăo vir a ser afetados pelo processo de integração (2).

Em 1988, quando Brasil e Argentina firmaram o protocolo de número 22 sobre produtos alimentícios, que complementava os protocolos número 2 e 3 (venda de trigo argentino e complementação do abastecimento alimentar), o governo do Estado do Rio Grande do Sul, pressionado pela Federação da Agricultura, elaborou lista de 36 produtos sensíveis. Estes produtos seriam deslocados do mercado caso houvesse a eliminaçáo tarifária que os protege da concorrência argentina. Essas resistências foram amenizadas progressivamente $e$, a partir de 1990, com o inesperado incremento das exportaçóes brasileiras para a Argentina - aumento de $143 \% \mathrm{em} 1991$ com relação ao ano anterior. O Brasil " náo apenas está ampliando rapidamente os seus mercados tradicionais, como está também conquistando novos mercados, inclusive na área agrícola (caso dos laticínios, ovos frescos, carne suína entre outros)" (Jank, 1992).

Provavelmente trata-se de situação passageira e a Argentina já tomou medidas visando a diminuir as importaçóes $\mathrm{em}$ geral e, em particular, as brasileiras. Portanto, não devemos minimizar aqueles diferenciais de custo de produção na área agrícola que não serão amenizados a médio prazo (Stülp, 1992).

Os produtores rurais brasileiro de médio e grande porte podem adaptar-se à nova realidade em construção no Mercosul, com a devida abertura da economia e as necessárias mudanças tecnológicas. No entanto, essas medidas são ineficientes para o pequeno produtor. Este utiliza - menos insumos e meios de capital que possam ser importados e estaria menos propenso à adoçăo da nova tecnologia por questóes financeiras e de risco" (Stülp, 1992).

Apesar de evoluçáo positiva da percepçáo do setor primário brasileiro em relaçáo ao pretendido com o Mercosul, devemos constatar que alguns setores seräo mais afetados que outros (3). É de todo aconselhável a clara visualização dos impactos setoriais, para os produtores que se tornarem incompetentes com a abertura de mercado terem a oportunidade de se atualizar tecnologicamente ou, na pior das hipóteses, dedicarem-se a outra atividade.

Exemplo que ilustra esta realidade é o caso do setor vinícola. A União Brasileira de Vitivinicultura - UVIBRA indica, através do Pro- 
jeto Provitis, que a renovaçáo dos vinhedos nacionais demandaria investimento de aproximadamente 200 milhóes de dólares (4).

Em definitivo, o que se exige dos poderes públicos envolvidos no processo de construção do Mercado Comum do Sul é o estabelecimento de canais de participaçáo de todos os setores de produção e de consumo interessados no processo e também das respectivas casas legislativas nacionais. O Estado deverá deixar claro o seu papel. Será ele um mero fator de desobstrução das forças econômicas ou, ao contrário, inspirando-se no caso da CEE, e de certa forma, nas experiências de desenvolvimento econômico nacional dos países latino-americanos, um indutor do desenvolvimento integrado?

\section{Notas}

1 Consultar PESCATORE, P., Le droit de l integration, Genebra, Ed. IUHEI, 1972. 99p.

2 Ver a reação do grupo brasileiro da Comissão Parlamentar Conjunta do Mercosul, transcrita na Gazeta Mercantil, " Política compensatória é sugerida para setores ameaçados pela integraçäo", São Paulo, 26 nov. 1992.

3 Sobre a mudança de expectativas dos setores produtivos do Rio Grande do Sul, consultar Federaçăo das Indústrias do Estado do Rio Grande do Sul, Termos de Refortncia sobre setores da ecomomia do Rio Grande do Sul face no processo de integrafaio, Porto Alegre, julho 1992.

4 Idem.

\section{Referências Bibliográficas}

AMORIM, C. L. N. \& PIMENTEL, R. P. S. C. Iniciativa para as Américas: o Acordo do "Jardim das Rosas", texto preparado para o Projeto 60 Anos de Pollatica Exterma, IPRI/USP, março 1992. 77p.

CAVALLO, D. O Estado de S.Paulo, Caderno Economia e Negócios, 14 nov. 1992, p. 8.

JANK, M. S. A importância do setor agroindustrial na integraçāo do Cone Sul: as cadeias sensíveis. In SEITENFUS, R. Org., A agropecudria brasileira e o Mercasul, Coleçāo Documentos, Série A Integraçăo Regional e o Mercosul, n.3, Instituto de Estudos Avançados da USP, novembro 1992. $153 \mathrm{p}$.

SEITENFUS, R. A. S. O góverno Itamar e o Mercosul. Folba de SAo Paulo, 25 out. 1992, p. 2.2.

SERRA, J. Percalços do Plano Cavallo. Jorrnal do Brasil, Caderno Negócios e Finanças, 28 out. 1992, p. 2.

STÜLP, V.J. Tecnologia, custos e competitividade no Mercosul: caso do trigo, soja, milho e arroz. In SEITENFUS, R. Org., $A$ agropecudria brasileira e o Mercosul, Coleçáo Docu- 
mentos, Série A Integraçāo Regional e o Mercosul, n.3, Instituto de Estudos Avançados da USP, novembro $1992.153 \mathrm{p}$.

THUROW, L. La Guerra del Siglo XXI. Buenos Aires, Ed. Vergara, 1992, p. 70.

\title{
Resumo
}

Após traçar as origens históricas e conjunturais do processo de integração na Bacia do Prata, o autor analisa as características do Tratado de Assunçăo, através de um organograma detalhado.

$\mathrm{Na}$ segunda parte, três questōes sem resposta säo colocadas aos leitores, ou seja, o processo de institucionalização envolvendo a constituiçāo de um espaço supranacional que estará diretamente vinculado aos objerivos do processo; as relaçōes do Mercosul com o Nafta e a definição de um quadro de cooperação e, finalmente, coloca a questão sobre o nível de participaçăo do Estado no processo integracionista sob a ótica da necessidade de reconversāo de certos setores econômicos

\begin{abstract}
In the first part of this article, the author, after delineating the historical and circumstancial sources regarding the process of integration in the Prata Basin, analyses the characteristics of the Traty of Asunción (Paraguay) through a detailed organizational chart.

In the second part, three open questions are discussed: (a) the process of institutionalization which involves the constitution of some supranationalization which invoves the constitution of some supranational space which will be closely related to the objectives of the process; (b) the relationships between the Mercosul and the Nafta and the definition of a cooperative program; (c) the level of participation of the State into the integrationist process under the clear need of a reconversion of some economic sectors.
\end{abstract}

Ricardo Seitenfus é coordenador do Projeto Mercosul/BRA/Fase 1 e professor visitante da Área de Assuntos Internacionais do IEA. 